\title{
Evaluation of Analgesic and Anti-Inflammatory Activities on Ethanolic Extract of Terminalia chebula Fruits in Experimental Animal Models
}

\author{
Md. Safkath Ibne Jami ${ }^{1}$, Zakia Sultana ${ }^{2}$, Md. Ershad $\mathrm{Ali}^{3}$, Mst. Marium Begum ${ }^{2}$, Md. Mominul Haque ${ }^{4^{*}}$ \\ ${ }^{1}$ Department of Pharmacy, University of Asia Pacific, Dhaka, Bangladesh; ${ }^{2}$ Department of Pharmacy, University of Rajshahi, Raj- \\ shahi, Bangladesh; ${ }^{3}$ Department of Chemistry, Dhaka College, National University, Dhaka, Bangladesh; ${ }^{4}$ Department of Chemistry \\ and Biomolecular Sciences, Macquarie University, Sydney, Australia.
}

Email: ${ }^{\text {mominul.chem@gmail.com }}$

Received September $5^{\text {th }}, 2013$; revised November $26^{\text {th }}, 2013$; accepted December $18^{\text {th }}, 2013$

Copyright (C) 2014 Md. Safkath Ibne Jami et al. This is an open access article distributed under the Creative Commons Attribution License, which permits unrestricted use, distribution, and reproduction in any medium, provided the original work is properly cited. In accordance of the Creative Commons Attribution License all Copyrights (c) 2014 are reserved for SCIRP and the owner of the intellectual property Md. Safkath Ibne Jami et al. All Copyright (C 2014 are guarded by law and by SCIRP as a guardian.

\section{ABSTRACT}

The present study was undertaken to evaluate the analgesic and anti-inflammatory activities of ethanolic extract of Terminalia chebula (commonly known as Haritaki) fruits in experimental animal models. The study was carried out using Swiss Albino mice (20 - 25 g) and Long Evans rats (100 - 150 g) of either sex. The analgesic activity of Terminalia chebula was assessed by using hot plate method. For the determination of analgesic effect, doses of ethanolic extract of Terminalia chebula used in the present study were $250 \mathrm{mg} / \mathrm{kg}$ and $500 \mathrm{mg} / \mathrm{kg} \mathrm{body}$ weight (BW). Anti-inflammatory effect was analyzed by carrageenan induced paw edema method with the administration dose of $300 \mathrm{mg} / \mathrm{kg}$ BW of animals. The analysis of experimental data was performed by statistical process of ANOVA to determine the variability of sample, while Dunnet's test was performed for evaluation of comparative analgesic and anti-inflammatory activity of Terminalia chebula with control and standard. The animals were divided into four treatment groups of six animals each and the "Mean \pm SEM" is the statistical identifiable value of the data and $P$ values $<\mathbf{0 . 0 5}$ was considered statistically significant. Hot plate test showed a significant increase in the mean reaction time to heat stimuli in hot plate method at both $250 \mathrm{mg} / \mathrm{kg}$ and $500 \mathrm{mg} / \mathrm{kg} \mathrm{BW}$ doses throughout the observation period in $\mathbf{3 0}$ minutes and 60 minutes after treatment, which was comparable to the standard ketorolac and control group. In carrageenan induced paw edema method, considerable results were found after determining the percentage change in paw volume in extract. In both cases of analgesic and anti-inflammatory study, \% inhibition of pain and inflammation were evaluated. Comparing with control, largest inhibition was found in inhibiting inflammation 5 hours after treatment, while the largest inhibition of pain was obtained in $\mathbf{3 0}$ minutes and $\mathbf{6 0}$ minutes after treatment of doses. The present study suggests that ethanolic extract of Terminalia chebula fruits has significant analgesic and anti-inflammatory activities.

\section{KEYWORDS}

\section{Terminalia chebula; Analgesic; Anti-Inflammatory; Hot Plate; Carrageenan Induced Paw Edema}

\section{Introduction}

To date the use of most commonly prescribed drugs for clinical management of analgesia has been limited because of the development of potential side effects including sedation, respiratory depression and dermatological reactions [1]. Due to their wide biological and medi-

${ }^{*}$ Corresponding author. cinal activities, higher safety margins and availability associated with plant based medicinal agent, more attention has been given on plant based drugs used in the traditional medicine. Because of these advantages, the medicinal plants have been widely used by the traditional medical practitioners in their day to day practice. According to WHO, more than $80 \%$ of the world population still depend mainly on herbal medicines and they have 
great demand in the developed as well as developing countries for primary healthcare [2].

A large number of plants and their constituents have been reported to possess analgesic and anti-inflammatory activities [3]. Terminalia chebula is one of the oldest medicinal plant species belonging to the family of Combretaceae [4]. It is commonly known as haritaki because it carries away all diseases or it is sacred to God Siva (Hari). It is always listed first in the Ayurvedic meteria medica because of its extraordinary powers of healing and is called the "king of medicines". Haritaki enjoys the prime place among medicinal herbs in India since ancient times. It is moderate to large sized tree, 15 - 25 meters in height and 1.5 - 2.5 meters in diameter, found throughout India, chiefly sub-Himalayan tracks, Assam and in all deciduous forests of India, specifically in Madhya Pradesh, Bihar, Assam and Maharashtra and in areas with light rain fall, but occasionally found in moist forest up to an altitude of 1500 meters [5].

Phytochemical studies of Terminalia chebula fruit extract show the presence of tannins like chebulic acid, chebulagic acid, chebulinic acid, corilagin, gallic acid, gallotannins and ellagic acid; fructose, amino acids, succinic acid, ascorbic acid, flavonol glycosides, triterpenoids, coumarin, betasitosterol, resin and anthroquinone $[4,6]$. The fruits of Terminalia chebula have been extensively used in Ayurvedic, Unani and Homoeopathic medicine. It is used in combination with Bahera in a herbal formulation called "Triphala" (three fruits) [4]. The dried ripe fruits have traditionally been used in the treatment of asthma, sore throat, vomiting, hiccup, bleeding piles, gout, heart and bladder diseases. Its paste with water is found to be anti-inflammatory, analgesic and has purifying and healing capacity for wounds [7]. It is given as adjuvant herb in chronic fever. It has been used to treat various ailments like hemorrhoids, dental caries, bleeding gums and oral ulcers, diarrhoea, gastroenteritis, malabsorption syndrome, vesicular and renal calculi, neuropathy, paralysis, memory loss, epilepsy, depression, diabetes, tumors, skin diseases, as well as intermittent fever, rheumatism, arthritis, gout, etc. [8,9]. The plant is reported to have antibacterial, antifungal, antiviral, antioxidant, hepatoprotective, cardioprotective, antidiabetic, hypolipidemic, antispasmodic, and various other activities [4-7]. The present study was designed to investigate the analgesic and anti-inflammatory activities of the ethanolic fruits extract of the Terminalia chebula so as to provide a scientific proof for the activity.

\section{Materials \& Methods}

\subsection{Plant Collection}

Fresh fruits of Terminalia chebula were used in this ex- periment. The plant specimens for the purpose of study were collected from the plant in Ayurvedic Nursery, Savar Bangladesh in the month of June, 2012. The specimen was identified and authenticated by the botanical officer of Bangladesh National Herbarium after 1 week of sample submission. After identification the plant specimens for research purpose were collected and then preserved in appropriate air circulation condition.

\subsection{Preparation of Extract of Terminalia chebula}

Shade dried fruits of Terminalia chebula were grounded to fine powder in an electric grinder. About 890 grams of grinded powdered material were extracted with $80 \%$ ethanol at a temperature of $60^{\circ} \mathrm{C}$ for about 48 hours. The mixture was filtrated in stepwise processes. While volume is reduced, it was then poured in watch glass of large surface area to make it more condensed and allow the rest solvent to evaporate. While the condensed filtrate turned into a gummy concentrate, it was obvious that we found the crude ethanolic extract. The crude ethanolic extract was further evaporated to dryness to obtain the dried ethanolic extract. The percentage yield of extract was $12.1 \% \mathrm{w} / \mathrm{w}$ with respect to the original air dried powder was obtained. The extract was finally stored in air tight container in a refrigerator at $2^{\circ} \mathrm{C}-8^{\circ} \mathrm{C}$ for further use in the experiment.

\subsection{Experimental Animals}

Swiss Albino mice (20 - 25 g) and Long Evans rats (100 - 150 g) of either sex were used for this experimental study. All the animals were acclimated to laboratory conditions for one week before the commencement of the experiments. The animals were housed under standard laboratory conditions (relative humidity 55\% - 65\%, room temperature $25.0^{\circ} \mathrm{C} \pm 2^{\circ} \mathrm{C}$, and alternate light-dark cycle of 12 hours each) and were allowed free access to standard dry pellet diet and filtered water. Animals were fasted overnight with free access to water prior to each experiment. The study was performed according to the CPCSEA (Committee for the Purpose of Control and Supervision of Experimentation on Animals) guidelines.

\subsection{Preliminary Phytochemical Tests}

The ethanolic extract of Terminalia chebula fruits were tested for different phytoconsituents like alkaloids, glycosides, saponins, tannins, protein, carbohydrates using standard procedures.

\subsection{Acute Oral Toxicity Studies}

Acute oral toxicity study was carried out for ethanolic 
extract of Terminalia chebula fruits using Acute Toxic Class Method as described in OECD (Organization of Economic Co-operation and Development) Guidelines.

\subsection{Preparation of Solutions (Extract \& Standard)}

To evaluate the analgesic activity of ethanolic extract of Terminalia chebula fruits by hot plate method, two different concentration of extract were used, 250 and 250 $\mathrm{mg} / \mathrm{kg}$ body weight. For preparation of $250 \mathrm{mg}$ sample, $125 \mathrm{mg}$ extract were dissolve in $5 \mathrm{ml}$ distilled water and $500 \mathrm{mg}$ sample were prepared by dissolving $250 \mathrm{mg}$ extract in $5 \mathrm{ml}$ distilled water. For the preparation of standard solution of $2.5 \mathrm{mg} / \mathrm{kg}$ body weight, $0.625 \mathrm{mg}$ Ketorolac powder was dissolved in $5 \mathrm{ml}$ distilled water.

For anti-inflammatory activity of ethanolic extract of Terminalia chebula fruits, required concentration of sample solution used was $300 \mathrm{mg} / \mathrm{kg}$ body weight. $4.5 \mathrm{~g}$ of powdered extract was dissolved in $30 \mathrm{ml}$ normal saline $(0.9 \% \mathrm{NaCl}$ solution) to prepare the sample solution for administering dose $300 \mathrm{mg} / \mathrm{kg}$ body weight. For the preparation of standard solution of $100 \mathrm{mg} / \mathrm{kg}$ body weight, $1.5 \mathrm{~g}$ Diclofenac sodium powder was dissolved in $30 \mathrm{ml}$ normal saline ( $0.9 \% \mathrm{NaCl}$ solution).

For preparation of injectable carrageenan suspension, $50 \mathrm{mg}$ carrageenan was accurately weighed and then it was dissolved slowly in WFI (water for injection) by gentle heating in water bath. Finally the volume was adjusted up to $5 \mathrm{ml}$ with WFI. The whole process will produce carrageenan $1 \%$ suspension. The suspension was kept in $50^{\circ} \mathrm{C} \pm 2^{\circ} \mathrm{C}$ in water bath for maintaining its homogeneous nature.

\subsection{Pharmacological Evaluation}

\subsubsection{Thermal Stimulus-Induced Pain (Hot Plate Test) in Mice}

The hotplate method is based on the use of thermal stimuli, where the latency of nociceptive reaction evoked by heat sensation of constant supra threshold intensity. For the determination of analgesic activity of ethanolic extract of Terminalia chebula, fruits, the animals were divided into four groups of six animals each. The test was carried out using hot plate apparatus (UGO Basile of Italy). Group I animals received water, animals of Group II received ketorolac $2.5 \mathrm{mg} / \mathrm{kg}$ body weight animal while animals of Group III and Group IV were treated with 250 and $500 \mathrm{mg}$ per kg body weight of the crude extract of following plants. The temperature of a metal surface was maintained at $55^{\circ} \mathrm{C} \pm 0.2^{\circ} \mathrm{C}$. Analgesic activity was assessed by placing the animals on a hot plate and observing the reaction time (paw licking, shaking and jumping) in seconds before and after drug admini- stration. The cut-off time was fixed to $15 \mathrm{~s}$ to avoid the damage to the paw of the animals. The latency was recorded at $0,30,60,120,180$ min following oral administration of the agents.

The reaction of heat induced pain was observed precisely. Environmental factors which contribute to the levels of anxiety within the mice: temperature, humidity, ventilation, noise intensity and lighting intensity were maintained at levels appropriate for mice.

\subsubsection{The Carrageenan Induced Paw Edema Method} Administration of carrageenan in the sub-planter region of rat's hind paw leads to the formation of edema in situ due to localized inflammation. About half an hour prior to the administration of carrageenan solution, experimental animals received test materials and standard antiinflammatory drug at appropriate doses. The volume of rat's paw was measured each hour up to five hours by means of mercury displacement method in travelling microscope assembly. The average percentage of increase in paw volume with time was calculated and compared against the control group. Percentage inhibition was calculated by using formula Vc-Vt/Vc $\times 100$. Where, Vc and Vt represent the average volume of control and treated animals respectively.

For the determination of anti-inflammatory activity of ethanolic extract of Terminalia chebula, fruits, the rats were divided into three groups of six animals each labelled from 1 to 6 . The test was carried out using plehysmometer (UGO Basile of Italy). Paw volume were measured up to a fox mark by normal saline $(0.9 \% \mathrm{NaCl}$ solution) displacement from the plethysmometer. Before treatment, a reading of paw volume for 0 hour was taken and recorded on the work sheet. Then control (normal saline), extract solution and standard are administered orally according to weight of rats.

After half an hour of drug administration, $0.1 \mathrm{ml}$ of $1 \%$ carrageenan solution was injected into sub-planner surface of the right hind paw of each rat of every group. Time of observation were 1, 2, 3, 4, 5 and 24 our after administration of treatment. Paw volume detected in plethysmometer were recorded precisely in every observation time.

\subsection{Statistical Analysis of Data}

The statistical analysis was carried by one way Analysis of variance test (ANOVA) to compare the effects on treatment groups before and after treatment with control group and Dunnet's multiple "t" tests were used to determine the effect of each treatment against control group. $P$ values $<0.05$ (95\% confidence limit) was considered statistically significant, using software SPSS. The null hypothesis $\left(\mathrm{H}_{0}\right)$ was assumed that there was no differ- 
ence in effects of treatments between the treatment groups compared with control group and alternate hypothesis $\left(\mathrm{H}_{1}\right)$ was assumed there was significant difference in effect of treatment between the treatment groups compared with control group.

\section{Results}

\subsection{Preliminary Phytochemical Screening}

The ethanolic extract of Terminalia chebula fruits found to contain tannins, flavonoids and tri-terpines and Phenolic compounds.

\subsection{Acute Toxicity Study}

Ethanolic extract of Terminalia chebula fruits was screened for toxicity by oral toxicity studies according to OECD guidelines taking three female mice with starting dose of $2000 \mathrm{mg} / \mathrm{kg}$ body weight and found to be non-toxic that is Category 5 or Unclassified and two test dose levels as low $250 \mathrm{mg} / \mathrm{kg}$, and high $500 \mathrm{mg} / \mathrm{kg}$ selected for experiment.

\subsubsection{Statistical Evaluation of Analgesic Activity of Ethanolic Extract of Terminalia chebula from Data of Hot Plate Method}

The mean of minimum reaction time of the heat induced pain was calculated using statistical software. There is standard error found for each mean value in sample number of 6 . These values are shown in Table 1 .

Here, 0 min is the reading found in hotplate before treatment. In the hot plate method, the ethanolic extract of Terminalia chebula at doses of $250 \mathrm{mg} / \mathrm{kg}$ and 500 $\mathrm{mg} / \mathrm{kg}$ showed significant increase in reaction time than control group in 30 and 60 minutes after drug administration which was comparable to the standard drug ketorolac. The maximum reaction time was found in $30 \mathrm{~min}$ for both 250 and $500 \mathrm{mg} / \mathrm{kg}$ body weight (11.133 \pm 1.388 and $9.217 \pm 1.122$ respectively).

With the mean value of reaction time from statistical measurement, two concentrations of extract $(250 \mathrm{mg} / \mathrm{kg}$ and $500 \mathrm{mg} / \mathrm{kg}$ ) were compared with the mean value of reaction time in control animals (Figures 1(a) and (b)).

Before treatment mean value of both concentration of extract were less than control. So the variations between two groups are omitted by obtaining the \% change in reaction time.

\subsubsection{Percentage Inhibition of Pain in Respect of \% Change in Reaction Time}

There are considerable value found after determining the \% change in reaction time in 30 minutes and 60 minutes after extract treatment. After 30 minutes of treatment, \% change in reaction time was $59 \%$ and $53 \%$ of Terminalia ccebula $250 \mathrm{mg} / \mathrm{kg}$ and $500 \mathrm{mg} / \mathrm{kg}$ extract respectively, while after 60 minutes of treatment it was $42 \%$ and $49 \%$ respectively (Table 2).

The \% change in reaction time of control was eliminated from the \% change in reaction time of other treatments, which indicates the $\%$ inhibition of pain.

Table 1. Change in reaction time of different treatments after doses administration in course of time (Values are Mean \pm SEM, $n=6$; significance at ${ }^{*} P<0.05$ as compared to the control).

\begin{tabular}{cccccc}
\hline Treatment & $0 \mathrm{~min}$ & $30 \mathrm{~min}$ & $60 \mathrm{~min}$ & $120 \mathrm{~min}$ & $180 \mathrm{~min}$ \\
\hline \multirow{2}{*}{ Control } & 8.450 & 8.117 & 7.967 & 8.608 & 8.683 \\
& \pm 0.819 & \pm 0.897 & \pm 1.010 & \pm 0.971 & \pm 0.912 \\
$\begin{array}{c}\text { Terminalia } \\
\text { chebula (250 }\end{array}$ & 6.983 & 11.133 & 9.933 & 8.175 & 7.700 \\
mg/kg BW) & \pm 0.580 & $\pm 1.388^{*}$ & $\pm 0.714^{*}$ & \pm 0.678 & \pm 1.028 \\
Terminalia & & & & & \\
chebula (500 & 6.008 & 9.217 & 8.967 & 6.817 & 6.400 \\
mg/kg BW) & \pm 0.376 & $\pm 1.122^{*}$ & $\pm 0.919^{*}$ & \pm 0.557 & \pm 0.289 \\
& & & & & \\
Standard & 7.460 & 8.542 & 9.483 & 10.750 & 9.367 \\
& \pm 0.645 & \pm 0.228 & \pm 0.309 & \pm 0.351 & \pm 0.512 \\
\hline
\end{tabular}

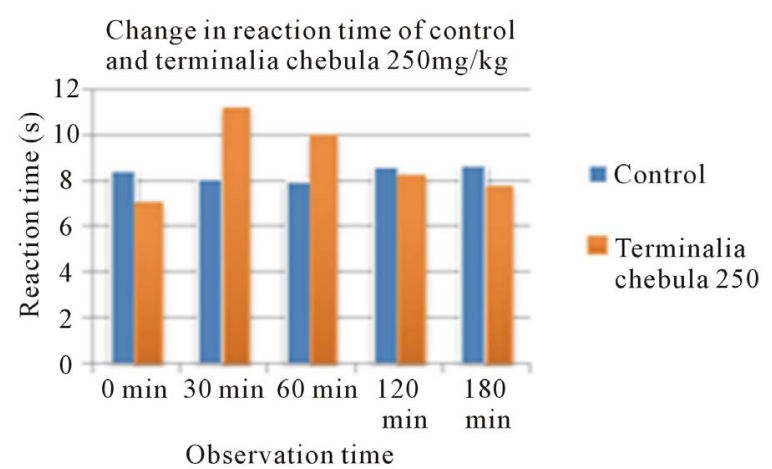

(a)

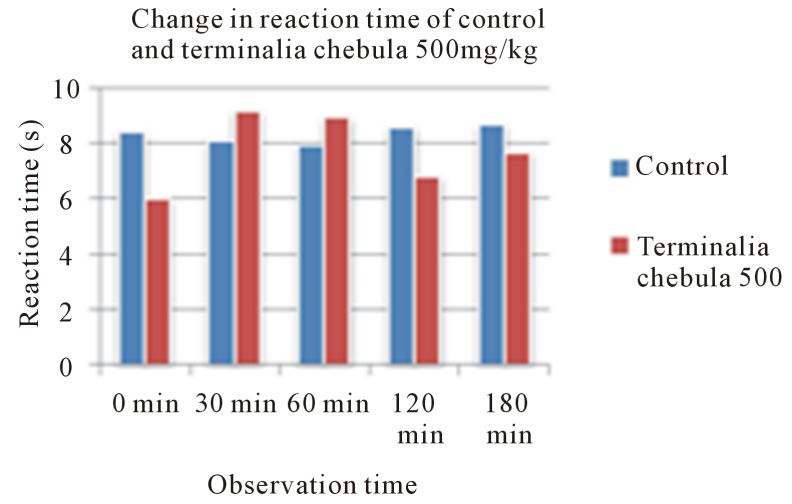

(b)

Figure 1. (a) Change in reaction time of Terminalia chebula $250 \mathrm{mg} / \mathrm{kg}$ compared with control; (b) Change in reaction time of Terminalia chebula $500 \mathrm{mg} / \mathrm{kg}$ compared with control. 
Table 2. \% change in reaction time after treatment of Terminalia chebula extract (250 and $500 \mathrm{mg} / \mathrm{kg}$ body weight).

\begin{tabular}{ccc}
\hline Treatment & $\begin{array}{c}\text { \% change in reaction } \\
\text { time in } 60 \mathrm{~min}\end{array}$ & $\begin{array}{c}\text { \% change in reaction } \\
\text { time in } 120 \mathrm{~min}\end{array}$ \\
\hline $\begin{array}{c}\text { Terminalia chebula } \\
(250 \mathrm{mg} / \mathrm{kg} \text { body })\end{array}$ & 59.43 & 42.24 \\
$\begin{array}{c}\text { Terminalia chebula } \\
(500 \mathrm{mg} / \mathrm{kg} \text { body })\end{array}$ & 53.41 & 49.25 \\
\hline
\end{tabular}

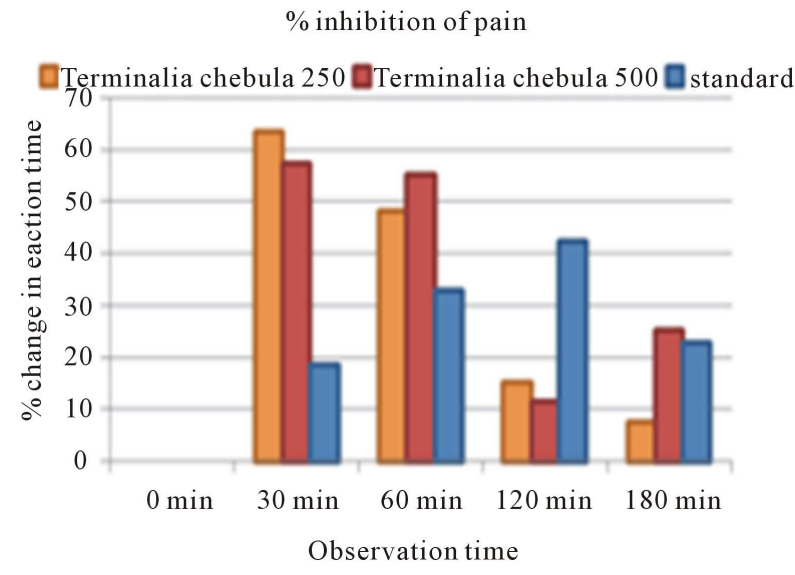

Figure 2. \% Inhibition of pain of Terminalia chebula 250 $\mathrm{mg} / \mathrm{kg}$ and $500 \mathrm{mg} / \mathrm{kg}$ and standard from control.

The diagram (Figure 2) shows how \% inhibition of pain was considerably increased than the standard in 30 minutes and 60 minutes. The ethanolic fruit extract of Terminalia chebula produced significant inhibition of pain. The inhibition was significant at the dose of 250 $\mathrm{mg} / \mathrm{kg}(63.370 \%)$ and $500 \mathrm{mg} / \mathrm{kg}(57.352 \%)$ to that of the standard drug, Ketorolac (19.23\%) at 30 minutes after treatment.

\subsubsection{Statistical Evaluation of Anti-Inflammatory Effect of Ethanolic Extract of Terminalia chebula Fruits from Data of Carrageenan Induced Paw Edema Method}

The increase in paw volume after sub-plantar injection of carrageenan was evaluated, with the assistance of mean value with standard error. The statistical value is determined by applying the software SPSS.

In Table 3, every treatment group consists of 6 samples and the "Mean \pm SEM" is the statistical identifiable value of the data. The analysis in comparing the value was with significance level " $\mathrm{P}<0.05$ ".

Here, 0 min is the reading found in plethysmometer before treatment. The ethanolic extract of Terminalia chebula produced dose-dependent and significant inhibition of carrageenan-induced paw edema. Extract showed slight increase in paw volume up to 2 hours after treatment, followed by rapid decrease in paw volume from 3 hours till 24 hours after extract treatment than control group which was comparable with standard (Diclofenac sodium $100 \mathrm{mg} / \mathrm{kg}$ body weight). The paw volume of carrageenan induced rat was increased till 2 hours due to the first phase and in the 5 hour the paw volume was decreased to $0.982 \pm 0.035$.

With the mean value of paw volume from statistical measurement, extract effect was compared with the mean value of reaction time in control and standard (Figures 3(a) and (b)).

\subsubsection{Percentage Inhibition of Inflammation in Respect of \% Change of Paw Volume}

There are considerable value of percent inhibition of inflammation was found by determining the percentage of change in paw volume in extract in 1 hour (21\%), 2 hour (27\%) and 3 hour (25\%) after treatment (Figure 4).

The \% change in paw volume of control was eliminated from the \% change in paw volume of other treatments, which indicates the \% inhibition of inflammation (Figure 5). The largest value of percentage inhibition of inflammation from control was found in 5 hour after treatment. The inhibition was significant at the dose of $300 \mathrm{mg} / \mathrm{kg}(52.625 \%)$ to that of the standard drug, Diclofenac (58.985\%).

\section{Discussion}

Hot plate method is the most significant method to evaluate the analgesic activity of a plant extract or chemical compound. The paws of mice and rats are very sensitive to heat at temperatures which are not damaging the skin. The responses are jumping, withdrawal of the paws and licking of the paws. The time until these responses occur is prolonged after administration of centrally acting analgesics. In our study, we used ketorolac $(2.5 \mathrm{mg} / \mathrm{kg}$ body weight) as a standard and two doses (250 mg/kg and $500 / \mathrm{kg}$ body weight) of the ethnolic extract of Terminalia Chebula fruits. Effect of Ethanol extract of Terminalia Chebula in hot plate method is shown in the Table 1. The analgesic activity is expressed as "mean

Table 3. Change in paw volume of different treatments after carrageenan administration in course of time (Values are Mean \pm SEM, $n=6$; significance at $* \mathbf{P}<0.05$ as compared to the control.

\begin{tabular}{cccc}
\hline $\begin{array}{c}\text { Observation period } \\
\text { (time after } \\
\text { treatment) }\end{array}$ & Control & $\begin{array}{c}\text { Terminalia chebula } \\
\text { extract }(300 \mathrm{mg} / \mathrm{kg} \\
\text { body weight) }\end{array}$ & Standard \\
\hline $0 \mathrm{hr}$ & $0.823 \pm 0.017$ & $0.852 \pm 0.021$ & $0.700 \pm 0.039$ \\
$1 \mathrm{hr}$ & $1.008 \pm 0.027$ & $1.033 \pm 0.078$ & $0.925 \pm 0.033$ \\
$2 \mathrm{hr}$ & $1.057 \pm 0.057$ & $1.090 \pm 0.069$ & $0.853 \pm 0.021$ \\
$3 \mathrm{hr}$ & $1.0942 \pm 0.056$ & $1.073 \pm 0.071^{*}$ & $0.838 \pm 0.016$ \\
$4 \mathrm{hr}$ & $1.079 \pm 0.044$ & $1.044 \pm 0.049^{*}$ & $0.803 \pm 0.023$ \\
$5 \mathrm{hr}$ & $1.087 \pm 0.061$ & $0.982 \pm 0.035$ & $0.7925 \pm 0.019$ \\
$24 \mathrm{hr}$ & $1.073 \pm 0.084$ & $0.978 \pm 0.043$ & $0.742 \pm 0.032$ \\
\hline
\end{tabular}




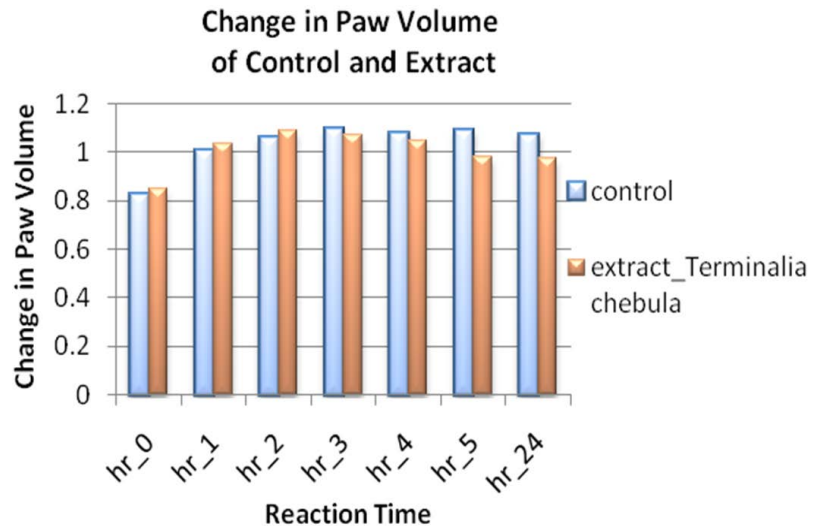

(a)

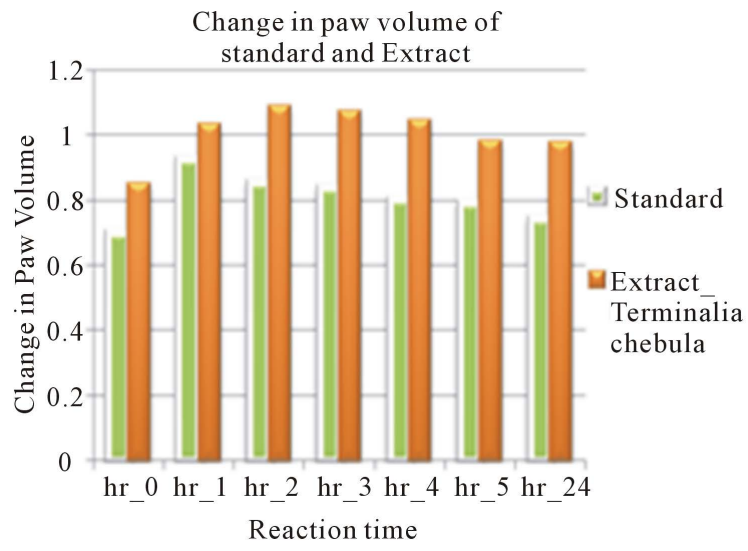

(b)

Figure 3. (a) Change in paw volume of Terminalia chebula extract $300 \mathrm{mg} / \mathrm{kg}$ compared with control; (b) Change in paw volume of Terminalia chebula extract $300 \mathrm{mg} / \mathrm{kg}$ compared with standard.

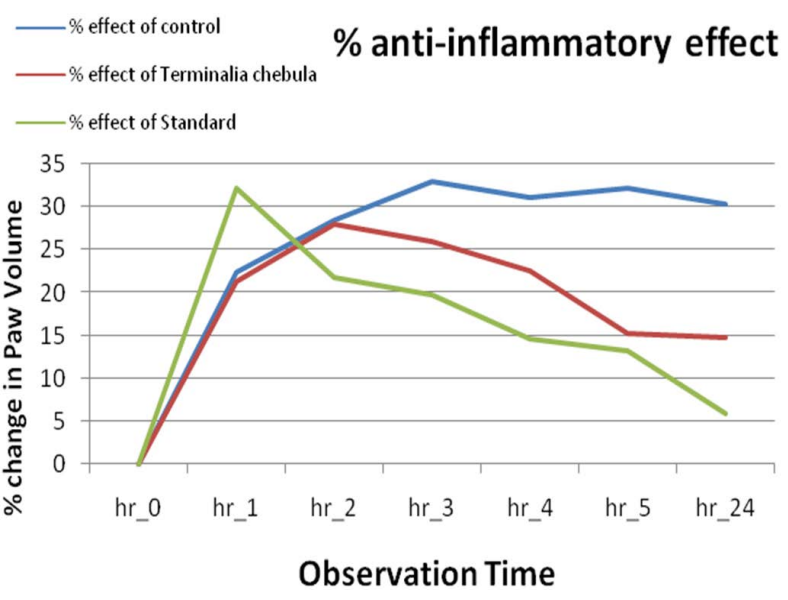

Figure 4. \% change in paw volume of Terminalia chebula extract $300 \mathrm{mg} / \mathrm{kg}$ and standard with control.

increase in latency after drug administration \pm SEM" relative to control. According to the table, maximum reaction time was found in 30 min for both 250 and 500

\section{$\%$ inhibition of inflammation}

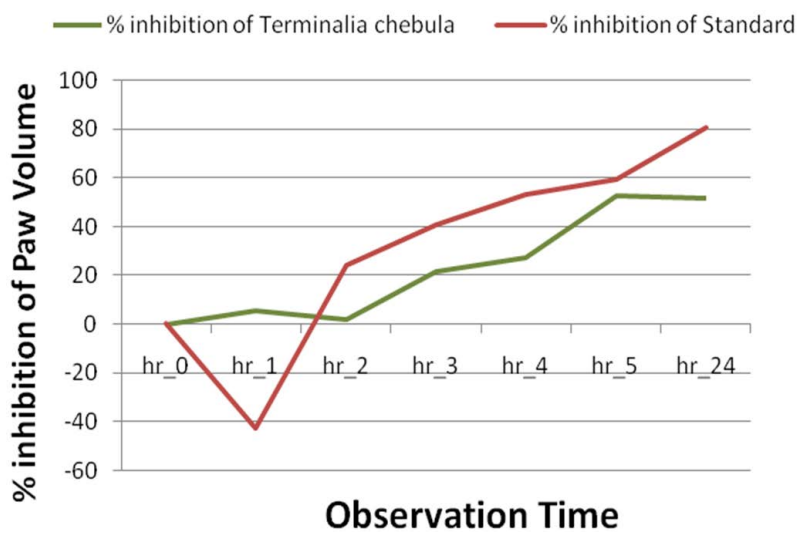

Figure 5. \% Inhibition of inflammation of Terminalia chebula $300 \mathrm{mg} / \mathrm{kg}$ from control.

$\mathrm{mg} / \mathrm{kg}$ body weight $(11.133 \pm 1.388$ and $9.217 \pm 1.122$ respectively). The ethanolic fruit extract of Terminalia chebula produced significant inhibition of pain. The inhibition was significant at the dose of $250 \mathrm{mg} / \mathrm{kg}$ body weight (63.370\%) and $500 \mathrm{mg} / \mathrm{kg}$ body weight (57.352\%) to that of the standard drug, Ketorolac $2.5 \mathrm{mg} / \mathrm{kg}$ body weight $(19.23 \%)$ at 30 minutes after treatment.

These results indicate that, Terminalia chebula extract at the dose of 250 and $500 \mathrm{mg} / \mathrm{kg}$ showed the significant $(\mathrm{p}<0.05)$ increase in latency time as compared to control and can produce significant analgesic activity. The duration as well as the intensity of analgesia was dose dependent. The plant extract showed a rapid onset of analgesic action at all two doses than as compared to standard at $2.5 \mathrm{mg} / \mathrm{kg}$ dose level.

The most widely used primary test for screening of anti-inflammatory agents is Carrageenan induced rat paw edema method [10]. Carrageenan is the phlogistic agent of choice for testing anti-inflammatory drugs as it is not known to be antigenic and is devoid of apparent systemic effects. The development of edema in the paw of the rat after injection of Carrageenan is believed to be biphasic event. The initial phase observed during the first hour is attributed to the release of histamine and serotonin; the second phase is due to the release of prostaglandin-like substances [11]. All these mediators include prostaglandins, histamine, bradykinins, leucotrienes and serotonin, which cause pain and fever [12]. Inhibitions of these mediators from reaching the injured site or from bringing out their pharmacological effects normally ameliorate the inflammation and other symptoms.

In our study we use Diclofenac sodium $100 \mathrm{mg} / \mathrm{kg}$ body weight as a standard drug. The anti-inflammatory activity was performed on carrageenan-induced rat paw edema model by external application of the ethanolic extract of Terminalia chebula (300 mg/kg body weight). 
One hour after the treatment, $0.1 \mathrm{ml}$ of $1 \%$ carrageenan was injected in the sub planter region of the hind paw of each animal in each group. Then after one hour the paw volume of the animals in each group was measured. According to the Table 3 (Change in paw volume of different treatments after carrageenan administration in course of time; Values are Mean \pm SEM), the paw volume of carrageenan induced rat was increased till 4 hour due to the first phase and in the 5 hour the paw volume was decreased $(0.982 \pm 0.035)$. The ethanolic extract of Terminalia chebula produced dose-dependent and significant inhibition of carrageenan-induced paw edema. The inhibition was significant at the dose of $300 \mathrm{mg} / \mathrm{kg}$ (52.625\%) to that of the standard drug, Diclofenac sodium (58.985\%).

The significant $(\mathrm{P}<0.005)$ anti-inflammatory activity exhibited by the extract of Terminalia chebula at the doses used $300 \mathrm{mg} / \mathrm{kg}$ body weight extract against edema induced by carrageenan in rats compared to the control group is an indication that, the extract have the possible pharmacological activity, but the exact mechanism of action of anti inflammatory activity was not performed yet. That is to be performed in future in support of relief from NSAIDs adverse effect.

The present results revealed a significant increase reaction time to heat stimuli, strongly suggests that the mechanism of the extract may be linked partly to cyclooxygenase and/or lipoxygenase inhibition. In addition, the flavonoids are known to inhibit prostaglandin synthetase [13]. Apart from flavonoids, tannins are also known to possess analgesic activity. Since prostaglandins involved in pain perception are inhibited by flavonoids, it could be suggested that reduced availability of prostaglandins by flavonoids and tannins present in Terminalia chebula fruits might be responsible for its analgesic and anti-inflammatory effect.

\section{Conclusion}

The present study concludes that the ethanolic extract of Terminalia chebula fruits possesses analgesic and antiinflammatory activities in mice and rats at the doses of $250 \mathrm{mg} / \mathrm{kg}$ and $500 \mathrm{mg} / \mathrm{kg}$ and, $300 \mathrm{mg} / \mathrm{kg}$ respectively. However, this is a preliminary study and further study needs to be carried out for knowing the possible mechanism of actions and isolation of active principle(s) responsible for such activities.

\section{REFERENCES}

[1] L. J. Rober and J. D. Morrow, “Analgesic-Anti-Inflammatory Agent and Drugs Employed in the Treatment of Gout," Goodman and Gilman's the Pharmacological Basis of Therapeutics, Mc Graw Hill Companies, America, 2001, p. 696.
[2] K. Sarabjit and R. K. Jaggi, “Antinociceptive Activity of Chronic Administration of Different Extracts of Terminallia bellerica Roxb. and Terminalia chebula Retz. Fruits,” Indian Journal of Experimental Biology, Vol. 48, No. 9, 2010, pp. 925-930.

[3] K. Dhiman, A. Gupta, D. K. Sharma, N. S. Gill and A. Goyal, “A Review on the Medicinally Important Plants of the Family Cucurbitaceae," Asian Journal of Clinical Nutrition, Vol. 4, No. 1, 2012, pp. 16-26.

[4] R. R. Chattopadhyay and S. K. Bhattacharyya, “Terminalia chebula: An Update,” Pharmacognosy Reviews, Vol. 1, No. 1, 2007, pp. 151-56.

[5] A. Gupta, A. K. Mishra, P. Bansal, R. Singh, S. Kumar and V. Gupta, "Phytochemistry and Pharmacological Activities of Haritaki-A Review," Journal of Pharmacy Research, Vol. 3, No. 2, 2010, pp. 417-424.

[6] C. L. Chang and C. S. Lin, "Phytochemical Composition, Antioxidant Activity, and Neuroprotective Effect of Terminalia chebula Retzius Extracts," Evidence-Based Complementary and Alternative Medicine, Vol. 2012, 2012, Article ID: 125247. http://dx.doi.org/10.1155/2012/125247

[7] K. R. Aneja and R. Joshi, "Evaluation of Antimicrobial Properties of Fruit Extracts of Terminalia chebula against Dental Caries Pathogen,” Jundishapur Journal of Microbiology, Vol. 2, No. 3, 2009, pp. 105-111.

[8] A. S. Hamed, M. C. Eswaraih, L. Madhavi, B. R. Maruthi and F. A. Syed, "Evaluation of Analgesic and Anti-Pyretic Activities of Ethanolic Extract of Terminalia pallida (EETP) Stem in Experimental Animals," Scholars Journal of Applied Medical Sciences, Vol. 1, No. 1, 2013, pp. 5-8.

[9] L. Joonmoni, K. B. Babul and S. Upama, “Analgesic and Antipyretic Activities of Terminalia chebula retz. Fruits Extracts in Experimental Animals," International Research Journal of Pharmaceutical and Applied Sciences, Vol. 2, No. 6, 2012, pp. 159-163.

[10] C. A. Winter, E. A. Rmley and G. W. Noss, “Carrageenan Induced Oedema in Hind Paw of the Rat as an Assay for Anti-Inflammatory Drugs," Experimental Biology and Medicine, Vol. 111, No. 3, 1962, pp. 544-547. http://dx.doi.org/10.3181/00379727-111-27849

[11] M. A. Antonio and A. R. M. Souza Brito, "Oral AntiInflammatory and Anti-Ulcerogenic Activities of a Hydroalcoholic Extract and Partitioned Fractions of Turnera ulmifolia," Journal of Ethnopharmacology, Vol. 61, No. 3, 1998, pp. 215-228. http://dx.doi.org/10.1016/S0378-8741(98)00049-X

[12] E. A. Asongalem, H. S. Foyer, J. Ngogang, G. N. Folefoc, T. Dimo and P. Kamtchouing, "Analgesic and Anti-Inflammatory Activities of Erigeron floribundus,” Journal of Ethnopharmacology, Vol. 91, No. 2-3, 2004, pp. 301308. http://dx.doi.org/10.1016/j.jep.2004.01.010

[13] M. Krek, "The Enigma of the First Arabic Book Printed from Movable Type,” Journal of Near Eastern Studies, Vol. 38, No. 3, 1979, pp. 203-212. http://dx.doi.org/10.1086/372742 